\title{
UK launches tumor bank to match maligned Biobank
}

British cancer researchers welcome plans to pool the UK's small cancer databases into a virtual tumor bank, even as the Medical Research Council (MRC), which will fund part of the project, is smarting from criticism about the UK Biobank database.

The tumor bank, launched by the National Cancer Research Institute, will receive $£ 1$ million for each of five years from three primary sources: the Department of Health, the charity Cancer Research UK and the MRC. The tumor bank will complement UK Biobank, a genetic database to help study gene-environment interaction in common diseases.

George Radda, chief executive of the MRC, says both databases will be valuable. "The new approach, using computational biology to handle vast amounts of data...is terribly important," he says. "It is really going to be the way of solving some of the major health problems."

A report from the House of Commons' Science and Technology Select Committee, published 25 March, slammed the MRC's allocation of funds and raised ethical concerns about Biobank, such as police access to the database. Critics of the project have recommended that legal safeguards be put in place to protect volunteers before recruitment begins, and that volunteers be made aware of the risks. They also recommend that the government invest in research into encryption techniques to ensure the data is secure.

Among cancer researchers contacted by Nature Medicine, news of the planned National Cancer Tissue Resource-as the tumor bank will be called-has received an enthusiastic response, however. "I think this is an excellent idea and well overdue," says John Timms, leader of the cancer proteomics group at the Ludwig Institute for Cancer Research, University College London.

In relatively rare cancers such as ovarian cancer, researchers have not been able to characterize molecular markers that would predict a patient's response to drugs. "The problem has been access to tissue coupled with very good clinical information," says James Brenton of the Hutchison/MRC Research Centre in Cambridge.

The tumor bank will take advantage of National Health Service resources to standardize sample collection and ensure tissue data are stored with the relevant pathological and clinical data. Tissue collection centers will be linked with processing centers, where researchers will perform a battery of analyses involving DNA, RNA and postissue microarrays to store and analyze large quantities of data provided by hundreds of patients in clinical trials, and store the data anonymously in a central information system.

Meanwhile, an MRC subcommittee on 4 April released a consultation docusibly proteomics. Investigators will use

ment on the council's future investment strategy, in which it recommended that the National Institute for Medical Research at Mill Hill, the oldest and largest of the MRC institutes, be scaled down and moved to another MRC site-possibly Addenbrooke's Hospital in Cambridge. According to Radda, this is part of the council's ongoing work to make sure that the institute remains viable in the post-genomic era, but the debate is still open. The consultation period ends in July, when the committee will consider its findings.

Laura Spinney, London

\section{Goats to de-liver cells for transplants in India}

The Indian government has agreed to fund research on the humble goat, Capra hircus, as a source of cells for liver transplants. If monkey trials planned for June confirm encouraging results in rats, goat hepatocytes may be transplanted into Indian patients suffering from acute liver failure before the end of the year.

"To our knowledge we are the first to show that goat is an alternative to pig for xenotransplantation," says Chittoor Mohammed Habibullah, head of the Center for Liver Research and Diagnostics at the Deccan College of Medical Sciences. He and his colleagues have also filed a US patent.

The Indian Department of Biotechnology, which spent Rs 50 million (roughly $\$ 1$ million) on the project over the last four years, has granted Rs 10.7 million for the monkey trials and for potential human experiments. The researchers' preliminary findings are extremely promising, says Manju Sharma, secretary to the department.

Based on in vitro comparative studies, goat hepatocytes are similar to human fetal liver cells in both morphology and biochemical function, says Habibullah. In terms of hepatic functions like albumin synthesis, bile formation and converting ammonia into urea, he adds, "goat hepatocytes are as good as liver cells from pig or human fetus." Last year, his group designed a bioreactor module with encapsulated goat hepatocytes-a crude bio-artificial liver support system like a dialyzer for kidney failure patientsand demonstrated its ability to detox-

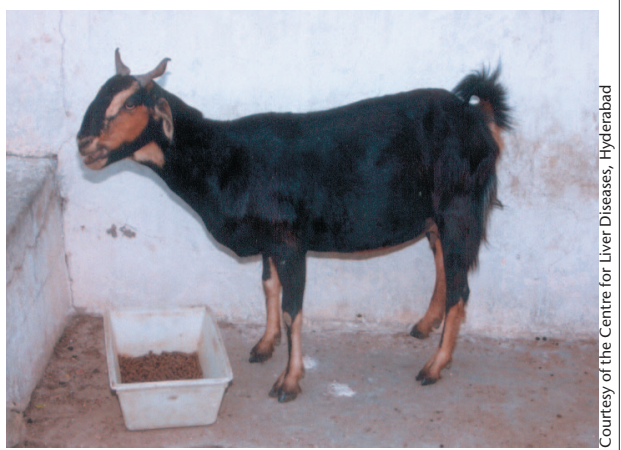

More than milk: Indian scientists find new use for the simple goat. glucose (Ind. J. Gastroenterol. 21, 55-58; 2002).

Although pig liver cells are readily available, various risks - such as immune rejection and transmission of endogenous retroviruses to recipients-limit their use. Because Indians have for centuries bred goats for their milk, the highly domesticated animals should have a lesser chance of harboring viruses harmful to humans, Habibullah says. Goat hepatocytes may carry their own share of risks, such as prions or ruminant virus infection, experts warn. But a screening of 20 goats by the Hyderabadbased Veterinary Biological Research Institute has turned up no known pathogens or zoonotic diseases.

Habibullah says the " $\alpha$-gal epitope" responsible for graft rejection is more pronounced on pig cells than on goat cells, suggesting goat cells are less likely to be rejected. For religious reasons, goats would also be more acceptable than pigs to Jews and Muslims.

K.S. Jayaraman, Hyderabad ify ammonia to urea and to metabolize 